\title{
Türkiye'de Hastanelerin Instagram Kullanımı: Medical Park, Acıbadem ve Memorial Sağlık Grupları Örneği
}

\author{
Fatma Senem Güngör (Dr. Öğr. Üyesi) \\ Başkent Üniversitesi İletişim Fakültesi \\ senemgungor@gmail.com \\ Orcid: 0000-0003-0959-5699
}

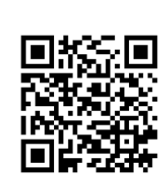

Başvuru Tarihi: 11.12.2019

Yayına Kabul Tarihi: 02.05.2019

Yayınlanma Tarihi: 22.07.2019

DOI: $10.17680 /$ erciyesiletisim. 495513

Güngör, F. S. (2019). Türkiye'de Hastanelerin Instagram Kullanımı: Medical Park, Acıbadem ve Memorial Sağlık Grupları Örneği. Erciyes İletişim Dergisi, 6 (2), 1309-1324.

DOI: $10.17680 /$ erciyesiletisim.495513

Öz

Akıllı telefonların, tabletlerin ve mobil uygulamaların yükselişi, özellikle yoğun çalışan sağlık profesyonellerine öğrenme ve iş birliği fırsatları sunmaktadır. Kamuya da birebir destek ve sağlık eğitimi sağlayan sosyal medya uygulamaları, sağlık ve sağlık hizmetleri alanında önemli bir gelişim süreci içindedir. Akıllı telefonların etkili kullanımı, doktorların ve hastaların 21. yüzyılda iletişim biçimlerinin bir parçasıdır. Klinik ve klinik dışı bilgi alışverişini kolaylaştıran ve mobil öğrenmeyi de destekleyebilen Instagram, tıp alanında sosyal ve mobil öğrenme biçimlerini kullanmaya teşvik etmektedir. Bu araştırmada, günümüzde 600 milyondan fazla kullanıcı tabanına sahip Instagram'a odaklanılarak, sağlık sektöründe Ankara'da yer alan en az 15.000 takipçi sayısına sahip üç özel hastanenin bu hizmeti nasıl kullandığı araştırılmıștır. Çalışma için belirlenen üç hastanenin söz konusu sosyal platformda Ocak-Eylül 2018 döneminde kendi kullanıcı kimlikleri ile bilgi paylaşımlarını nasıl dijital döneme uyarladıkları incelenmiş ve "yaşam biçiminin temsili", "perde arkası" ve "aile ve çocuk" temaları altında aktif bir biçimde kullandıkları belirlenmiştir.

Anahtar Kelimeler: Sosyal Medya, Sağlık, Instagram, Hastaneler, İletişim. 


\title{
Instagram Usage of Hospitals in Turkey: Case Study of Medical Park, Acıbadem and Memorial Health Groups
}

\author{
Fatma Senem Güngör (Asst. Prof. Dr.) \\ Başkent University Faculty of Communication \\ senemgungor@gmail.com \\ Orcid: 0000-0003-0959-5699
}

Date Received: 11.12.2019

Date Accepted: 02.05.2019

Date Published: 22.07.2019

DOI: 10.17680/erciyesiletisim.495513

\section{Abstract}

The rise of smartphones, tablets and mobile apps is an important development in health and healthcare, particularly social apps that provide learning and collaboration opportunities to busy health professionals and health education for the general public. Effective use of smartphones is part of how doctors and patients communicate in the 21st century. This paper focuses on one social media and networking service that was launched in 2010 and active user base is reached 600 million by the end of 2017, namely Instagram. In medicine, Instagram is finding a niche among health professionals that use hospital-specific and dedicated accounts and groups on these platforms to communicate and encourage social and mobile forms of learning. Instagram is free and easy-to-use apps that facilitate all sorts of clinical and non-clinical exchanges, and can also support mobile learning. This paper focuses on the content of images of three Turkish hospitals' Instagram accounts on January-September 2018 which provide health-related information in the today's digital era.

Keywords: Social Media, Health, Instagram, Hospitals. 


\section{Giriş}

Her gün 95 milyon fotoğraf ve videonun paylaşıldığı Instagram'da bugüne kadar 40 milyardan fazla resim ve video kullanılmıştır. ${ }^{1} \mathrm{Bu}$ zengin medya içeriği, büyük çaplı halk sağlı̆ı çalışmaları için de verimli bir veri kaynağı haline gelmiştir (Boulos vd., 2014, 229). Sosyal medya kullanımı, her geçen gün artan çevrimiçi kullanıcıların sayısı ile sosyal etkileșimi artırmakta, değișen toplumsal yaşamın izdüșümüne dönüşmektedir. Estetik kaygıların ön plana çıtığı günümüz toplumunda ise Instagram dermatolojik gelişmeler, obezite cerrahisi ve sağlıklı yeme alışkanlıkları gibi alanlardaki gelişmelerin ilgililere duyurulması için elverişli bir ortam yaratmaktadır (Boulos vd., 2011, 10).

Sosyal medya görüntü verileri, büyük ölçekte yazılı durum güncellemelerinde paylaşılan tamamlayıcı verilerdir. Örneğin; sosyal bir etkinlik sırasında veya sonrasında, etkinlikhakkındayayınlanacakolanbilginotunun hashtag "\#” kullanılarak yazılı bir biçimde paylaşılmasının yanı sıra, akıllı telefonlarla çekilen görüntülerin ve/veya videoların paylaşılması da tercih edilir olmuştur. Kullanıcı tarafından paylaşılan söz konusu görüntülere yönelik yapılacak açıklamalar da aynı platform üzerinden paylaşılabilmektedir. Derin öğrenme (Karpathy ve Fei-Fei, 2014, 1414) ile ilgili gerçekleșen ilerlemeler sayesinde, görüntüdeki nesneleri otomatik olarak anlamak ve yazılı açıklamalar üretmek mümkün olmuştur. Otomatik resim tanıma araçlarının kullanımı, dilin sağladığı olanakların görüntü analizinde kullanılmasına imkan sağlamaktadır. Örneğin; arama motorlarında yapılan dilsel aramada kullanıcıların aynı kavrama ulaşmak amacıyla kullanabilecekleri farklı kelimelerin tümü taramada kullanılabilmektedir. Bu araştırmada "dil”, hem İngilizceyi hem de Türkçeyi ifade etmektedir ve aynı zamanda kullanıcıların "\#health" ve "\#sağlık” gibi etiketleyebilecekleri farklı ve tutarsız kelimelere atıfta bulunmaktadır.

Sosyal medya, yaşam biçimini ve sağlık verilerini bireysel düzeyde birleştiren büyük çaplı çalışmaları da mümkün kılmıştır. Örneğin; Sadilek ve Kautz (2013, 637-646), bir kullanıcının sağlığını Twitter kullanımına göre tanımlamak için bir sınıflandırıcı oluşturmuşlardır. Başka çalışmalarda da depresyon, uyku sorunları (McIver vd., 2015,140 ) ve yeme bozuklukları (Walker vd., 2015, 157-163) gibi birçok hastalık da sosyal medya verileri kullanılarak incelenmiştir. Görüntüler ve diğer zengin multimedya verileri, sosyal medyada üretilen ve paylaşılan içeriğin önemli bir kısmını oluşturmasına rağmen, belirtilen araştırmalardaki verilerinin tümü görsel içerik yerine yazılı metinlerden oluşmaktadır. $\mathrm{Bu}$ çalışmada ise hastanelerin Instagram hesaplarında yayınladıkları sağlıkla ilgili konulardaki görsel veriler içerik analiz yöntemi ile incelenmiștir.

Sosyal medya, sosyal, ekonomik ve kültürel yapıları etkileyerek birey ve toplumların ilişki biçimlerini değiştirmekte, iletişimi zaman ve mekândan bağımsızlaştırarak dünyayı "küresel köy" (Powers ve McLuhan, 2015) haline getirmektedir. Bu noktada bireyin yalnızca etkilenen değil etkin; yalnızca paylaşımları seyreden değil içerik ve paylaşım üreten bir dönüşüme uğradığını söylemek mümkündür. Boulos ve ark. 2006 (6) yılında sağlık ve sağlık hizmetleri alanında kullanılan "blog" ve "podcastleri" incelediklerinde, sağlı sektörünün nasıl sosyal medyada değiştiğini belirtmişlerdir. O zamandan bu yana, giderek artan sayıda sosyal medya ve ağ hizmetleri piyasaya sürülüp, sağlık ve sağlık hizmetleri alanlarında popüler hale gelmişlerdir. Facebook, Instagram, Twitter ve Linkedin gibi sosyal medya araçları yerleşik pozisyonlar kazanarak sağlık ve sağlık hizmetleri alanında kullanım oranlarını arttırmışlardır. 
Fotoğraf paylaşımı ve mesaj uygulamaları, mobil devrimin bir parçası olup; yazılı, sesli ve görsel bilgilerin paylaşımı ve iletimini büyük ölçüde değiştirmişlerdir.

\section{Instagram}

We Are Social ve Hootsuite firmaları tarafından her yıl 238 ülkeden toplanan sosyal medya kullanımı verilerine Şubat 2018'de yayınlanan "Digital in 2018 Global Overview" araştırma raporunda ${ }^{2}$ yer verilmiştir. Rapor, internet, mobil ve sosyal medya kullanıcı bilgileri hakkında önemli istatistikler ortaya koymuştur. Raporda internet ile beraber mobil internet kullanımının da hızla arttığını görülmektedir. Türkiye'nin İnternet ve sosyal medya kullanım istatistikleri incelediğinde ise Türkiye'de nüfusun \% 67'lik kısmını oluşturan 54 milyon kişi İnternet'e bağlanmaktadır; aktif sosyal medya kullanıcı sayısı da 51 milyona ulașmıştır. Yapılan araştırmalara göre; kullanıcılar gün içerisinde ortalama 7 saatini bilgisayar karşısında, 3 saatini telefon üzerinden İnternet'e bağlanarak ve 3 saatini sosyal medya platformlarında geçirmektedir. Televizyon karşısında geçirilen vakit ise ortalama 2 saattir. Ülke genelinde en çok kullanılan sosyal medya kanalları Youtube ve küçük bir fark ile takip eden Facebook'tur. Diğer popüler sosyal medya kanalları ise Whatsapp ve Instagram'dır.

2010'da piyasaya sürülmüş bir sosyal ağ hizmetidir. Şu anda California, ABD'de yerleşik Facebook Inc.'e bağlı bir kuruluş olan olan Instagram, takipçilerine kendi fotoğraflarını iletmelerini sağlayan ve diğer fotoğrafları yeniden ileten bireylerden, organizasyonlardan, satıcılardan ve işletmelerden oluşan kullanıcıların yer aldığı bir sosyal paylaşım sitesidir. Android ve iOS platformları için bir uygulama olan Instagram'a, aynı zamanda web tabanlı zaman tüneli sayesinde masaüstü bilgisayarlardan ve dizüstü bilgisayarlardan da herhangi bir Web tarayıcısından da erişilmektedir.

Instagram kullanıcıları, zaman tünellerindeki resim metinlerini ve etiketleri olan fotoğraflarını, videolarını kolaylıkla paylaşabilirler. Zaman tüneli ziyaretçileri ve takipçileri, paylaşımları "beğenebilir" veya "yorum" yapabilirler. Ayrıca, Instagram uygulamasında yer alan Direct Message (DM) ile kullanıcılar kişilere veya gruplara özel mesaj gönderebilir, "etiketler" (\#) ile gönderi konusu aynı olan ilgili yayınlar ile bağlantı sağlayabilirler. Instagram'ın Ekim 2010'da piyasaya sunulduğu tarihten itibaren yaklaşık 800 milyon aktif kullanıcısı 50 milyar fotoğraf paylaşmıştır. ${ }^{3}$

Instagram, kitlelere ulaşmak için şeffaf ve işlevsel bir platform sağlamaktadır. Bu yeni sosyal ă̆ platformu mesleki örgütlere, genç nüfusa, özellikle de kadınlara ulaşmak için bir fırsat sunmaktadır. Bu fırsat, genellikle politikacılar ve siyasi gruplar tarafından destek kampanyaları için kullanılmaktadır. Örneğin; ABD’nin 44'üncü Devlet Başkanı Barack Obama kampanya bilgilerini belgelemek için yaklaşık 3 milyon takipçi ve 176 yayınla Instagram'ı kullandı ve siyasi takipler konusunda sürekli olarak ilham verdi (Başkanın Eşi Bayan Michelle Obama da yaklaşık 700.000 takipçiyle ve 116 yayınla kampanyaya destek verdi). ${ }^{4}$ Türkiye`deki politikacılar ve siyasi partiler de potansiyel seçmen kitleleri ile daha kişisel bir seviyede bağ kurmak için Instagram ve diğer sosyal ağ sitelerini kullanmaktadır.

Omnicore'e göre, Instagram sosyal medyada mobil foto paylaşımı konusunda hızla öne çıkmaktadır. 2018 istatistiklere göre, ${ }^{5}$ Instagram kullanıcılarının \% 80'i ABD dışında ve çoğu 18-29 yaş aralığında olup, kadın kullanıcılar erkek kullanıcılardan 
fazladır. Örneğin; 136 milyon takipçi sayısı ile ilk sırada yer alan Selena Gomez'i, 125 milyon ile Christiano Ronaldo takip etmektedir. Kylie Jenner ise bebeği ile ilk resmini yayınlayarak yaklaşık 18 milyon beğeni alarak rekor kırmıştır.

2016 yılında Kristal Elma Yaratıcılık Festivali'nde konuşan Instagram EMEA (Europe, Middle East and Africa) Bölgesi İș Geliștirme Yöneticisi Amy Cole, ${ }^{6}$ Instagram'ın yerel işletmelerin, müşterileri ile etkili bir biçimde iletişim kurmasına olanak sağladığını belirtmiştir. Cole, 22 milyonluk Instagram Türkiye kullanıcısı sosyal ağın en fazla kullanıldığı ABD, Rusya ve Brezilya'nın ardından 4'üncü ülke konumunda olup, bu olanaklardan yararlanabilecek potansiyeli çok yüksek bir ülke olduğunu sözlerine eklemiştir. Bununla birlikte, Türkiye' de Ağustos 2017 yılında yapılan bir araștırmaya ${ }^{7}$ göre Instagram, en çok konuşulan sosyal medya hesapları arasında toplam 91 bin 279 haber ile ülke medyasında üçüncü sırada yer almıştır.

\section{Instagram ve Sağlık Alanı}

Instagram'ın kullanımı eğitici/bilgilendirici ve motive edici/destekleyici uygulamalar olmak üzere iki ana kategoriye ayrılmaktadır. Bununla birlikte Instagram kullanıcılarının beş temel sosyal ve psikolojik motivasyonu bulunmaktadır (Lee vd,. 2015, 552-556). Bunlar, sosyal etkileşim, arşivleme, kendini ifade etme, kaçınma ve göz gezdirmedir. Instagram, genellikle hızlı yükleme süreleri sayesinde özellikle görüntü yükleme ve indirme işlemlerinde kullanım kolaylığı sunmaktadır. Instagram'ın kamusal zaman tüneli özelliği, Sağlık Bakanlığı gibi sağlık kuruluşlarının, görsel açıdan zengin halk sağlığı mesajlarını takipçilerine ve hizmeti kullanan binlerce potansiyel okuyucuya ulaştırmalarını ve yaymalarını sağlamaktadır. Ayrıca, fotoğraf paylaşım platformları, kamu sağlı̆̆ı krizlerine yönelik bilgi alışverişi için de kullanılmaktadır.

Instagram, hem halkı eğiten ve ilgilendiren, görsel açıdan zengin sağlık mesajlarıyla hem de halk sağlığına yönelik krizlerdeki ve doğal felaketlere yönelik risk iletişimindeki rolüyle Dünya Sağlık Örgütü (WHO) ve diğer halk sağlı̆ı kurumları tarafından kullanılan araçlardan biri olmaya devam etmektedir. Örneğin; WHO, Filipinler'de Typhoon Haiyan ile ilgili bilgileri Instagram'ı kullanarak paylaşmıştır (Cool vd., 2015, 86-90).

Instagram üzerinde sağlık ile ilgili çalışmalar geçtiğimiz yıllarda artmıștır. Örneğin; Yi-Frazier ve ark. (2015, 1372-1382) Instagram'da tip 1 diyabetli ergenlerin hastalıkla ilgili tartışmalarını, fotoğraf paylaşımlarını ve bireyler arası destek konularını incelemişlerdir. Diğer bir çalışmada Al-Eisa ve ark. (2016), Instagram'ın bir ev egzersiz programıla birlikte motivasyonel bir yöntem olarak kullanılmasının uygun bir fiziksel aktivite seviyesine taşındığı ve bunun devamlılığını sağlamak için cazip ve etkili olabileceği sonucuna varmışlardır. Bununla birlikte, Tiggemann ve Zaccardo (2015, 61-67), Instagram'da fit olmayı teşvik eden görüntülerin (izleyicileri daha sağlıklı bir yaşam biçimine yönlendirmek için egzersiz ve sağlıklı gıdaları teşvik eden), düşük benlik saygısına sahip belirli kullanıcılarda bu tür görüntülere maruz kaldıkları için beden algılarına yönelik olarak istenmeyen etkiler oluşturabileceğini belirtmiştir.

\section{Instagram ve Hastaneler}

Öğrenme, temelde insanların birbirlerinin bilgi kazanımını desteklediği ve genişlettiği sosyal bir faaliyettir (Vygotsky, 1978) ve son yıllarda, mobil teknoloji ve 
sosyal medya aracılığıyla da mümkün olan dağıtılmış öğrenme biçimlerini açıklamak için yeni teoriler ortaya çıkmıştır. Dijital biçimler halindeki destekler, öğrencilerin kişisel cihazları kullanarak yeni bilgiye eriştiği yerlerde ortaya çıkmaktadır (Wheeler, 2015). Akran öğrenimi ve bilgi üretimine yönelik yeni ve gelişen biçimler nedeniyle; uzmanlar ve yeni başlayanlar arasındaki güç farklılıklarının giderek azaldığı düşünülmektedir. Instagram, bu tür öğrenim gereksinimlerini karşılamakta ve yükselen popülaritesiyle de -özellikle de genç nesiller arasında- akran öğretimi ve bilgi yayılımına yönelik geniş çapta kullanımı, sürekliliğini sağlamaktadır (Gauthier vd., 2016, 575-576).

Aha Medya Grubu'ndan Ahava Leibtag'a göre, Instagram'da bir resim bin kelimeye -ve kullanıcıya- değer olabilir. ${ }^{8}$ Leibtag, günümüzde Instagram'ı tanınırlık ve etkileşimli iletişim için kullanan hastaneleri incelediklerinde, birçok hastanenin Instagram üzerinde etkili olmadığını belirtmiştir. Bu araştırma için 2018 yılı Ocak-Eylül aylarında Ankara'da yer alan hastanelerin Instagram sayfaları incelendiğinde de Leibtag'ın belirttiği sonuç ile karşılaşılmıştır. Örneğin; üniversite hastanelerinin çoğu (Gazi Üniversitesi Hastanesi, Ankara Üniversitesi Hastanesi ve Hacettepe Üniversitesi Hastanesi dâhil, Şubat 2018) Instagram'da bir varlık göstermemektedir. Üniversite hastanelerinin haricindeki özel hastaneler sosyal medya çalışmalarını Facebook ve Twitter üzerinden yürütmektedir. Yapılan araştırma sonucu, söz konusu özel hastanelerin kendi sosyal medya hesaplarında halk tarafından bilinirliliklerini arttırmak amacı ile sosyal etkinliklerine ait resimleri çoğunlukla paylaştıkları görülmüştür. Bunun yanı sıra ileri tarihli etkinliklerin reklamları ile güneșten korunma veya cilt kanserinin erken teşhisi gibi sosyal içerikli paylaşımlarda bulunmuşlardır.

Çevrimiçi kullanıcılarının görsel içeriğe cevap verme sayısının her geçen gün büyümesi ile hastaneler Instagram'daki varlıklarını çeşitlendirmekte ve kullanıcı sayılarını etkileşimli iletişim ile arttırmaya çalışmaktadır. Türkiye'de birkaç hastane hali hazırda bunu gerçekleştirmektedir. ABD'de hastaneler, takipçilerine sağlık, bakım, personelin faaliyetleri/profilleri ve/veya başarılıve ilham verici hasta öyküleri hakkında haftalık bilgiler vermektedir. Örneğin; Seaatle Children's Hospital 2108 yaz ayında Seattle Sea Hawks Amerikan futbol takımı ile ortaklașa düzenledikleri bağıș kampanyası sonunda kanserli çocuklar için 2 milyon dolarlık bir bağış toplamış ve projenin her aşamasını Instagram üzerinden duyurmuştur. ${ }^{9}$ Bu hastaneler, içerik bakımından zengin ve çekici hikâyeler geliştirmek için Instagram’ı kullanmaktadır. Sonuç olarak, hastalarla daha kişisel bir seviyede bağlantı kurmaktadırlar.

Türkiye'de Instagram'ı aktif kullanan hastaneler, sağlıklı yaşamı teşvik etmek, bireysel hizmet hatları oluşturmak, sağlıklı yaşam etkinlikleri için reklam yayınlamak vb. için söz konusu sosyal medya platformunu kullanmaktadırlar. Aynı zamanda Instagram'ı, genç kuşaklara öneriler sunmak için kullanarak sağlıklı yaşam bilinci oluşturmaktadırlar. Yapılan araştırma sonucu, belirlenen hastanelerin Instagram hesaplarında kullandıkları görsel ve yazılı iletiler birbiriyle ilişkili ve hedef odaklıdır.

Hastalarla klinik ortam dışında iletişim kurmanın etkili yollarını bulmak, giderek kritik ve zor hale gelmiştir. Geçmişte egemen olan posta ve telefon gibi iletişim kanalları, yeni medya kanalları tarafından desteklenmekte ya da değiştirilmektedir. Sosyal medyadaki içeriğin çoğu hastaları ve aileleri, komşuları, çalışanları ve potansiyel olarak rakipleri de dâhil olmak üzere hastane zümresi tarafından üretilmektedir (Miller ve Tucker, 2013, 52-70). 
Güçlü bir sosyal medyanın varlığı, hastanelerin itibarını ve hastaları cezbetme, olumlu hissetmelerini sağlama becerisini destekleyebilir. Ayrıca, rekabetin çok yüksek olduğu günümüz dünyasında özel hastaneler pazarlama savaşında kendilerine yeni stratejiler yaratmalı ve uzun vadede marka tanınırlıklarını sosyal medya üzerinden inşa etmelidirler (Sanlav, 2014, Bilgin 2013, 25-26). Örneğin; hastalar, sosyal medya faaliyetleri olan hastanelerin ileri teknolojileri ve en ileri tedavileri sunma ihtimalinin daha fazla olduğunu düșünebilirler.

\section{Metodoloji}

Bu incelemenin başlangıç noktası, 'Instagram' anahtar sözcüğü kullanılarak PubMed aracılığıyla toplanan makalelere dayanmaktadır. 2017 yılı Nisan ayı ortalarından itibaren 90'dan fazla PubMed endeksli kayıt bulunmuştur. Ayrıca, internet ortamında sağlık ve Instagram konularıyla ilgili birçok araştırma kaynakları da incelenmiştir. Söz konusu araştırmalar ve analizler sonucu, ilgili çalışma, yalnızca Instagram’ı kapsamakta olup, diğer sosyal ağ hizmetleri ile ilgili bilgi içermemektedir.

Instagram'ın, ilgi alanlarına göre oluşturulmuş etiketlerin veya kullanıcı isimlerinin sorgulandığı iki arama motoru bulunmaktadır. Instagram'ın söz konusu arama mekanizmaları sayesinde, Türkiye'de ki en fazla takipçi sayısına sahip, popüler ve profesyonel sağlık kuruluşları ile tanınmış hastaneler/sağlık grupları sorgulanabilmiştir. Ayrıca, kuruluşların Instagram'da takip edilmelerine yönelik bir bağlantı bulmak için web siteleri de incelenmiştir.

$\mathrm{Bu}$ bilgiler doğrultusunda; söz konusu araştırma için, Instagram hesapları en az 15.000 kişi tarafından takip edilen ve Ankara ili sınırları içinde yer alan özel hastaneler belirlenmiş ve içlerinden en çok takipçi sayısına sahip üç özel hastane seçilmiştir. Liste, SGK'nın Ankara ilinde yer alan anlaşmalı özel hastaneler listesine ${ }^{10}$ dayanılarak oluşturulmuştur. Bunlar sırasıyla, 18.800 takipçi sayısı ile Medical Park, 26.000 takipçi sayısı ile Acıbadem ve 31.200 takipçi sayısı ile Memorial Sağlık gruplarıdır.

Sağlık hizmetleri bağlamında, sosyal medya birçok akademik çalışmada incelenmiştir (Chou vd., 2009, Chou vd., 2011, Kravitz ve Bell, 2013, Suby, 2013, Moorhead vd., 2013). Bununla birlikte, literatürde Instagram'ın hastaneler bağlamında kullanılması hakkındaki araștırmalar yetersizdir. $\mathrm{Bu}$ nedenle bu çalışmada, Instagram'da hastane ile ilgili hangi içeriklerin var olduğu sorusu sorulmuştur. Instagram'ın etiket arama motoru aracılığıyla "\#hastane”, “\#doktor", "\#sağlık", "\#health" ve "\#hospital" anahtar kelimeleri ile Instagram'da tarama yapılmıştır.Instagram'daaranankullanıcılarpopülerliklerinegörefiltrelenemedikleri için isimlerinde veya profillerinde "sağlık" veya "hospital" bulunan en popüler kullanıcıları belirlemek üzere bir web ara-yüzü olan Quickagram kullanılmıştır.

"Etiketler" araması yapılırken, "etiketler" standart olmadı̆̆ı ve ilgi düzeyi veya popülerlik düzeyine göre filtrelenemediği için sonuçları nitelendirmek zordur. Ayrıca, takipçilerinin sayısı da bu araştırmanın konusu olarak seçilerek araştırılmıştır. Ardından, hastanelerin hesaplarındaki Ocak-Eylül 2018 içindeki gönderiler tespit edilmiş ve taranmıştır. Bu araştırmayı takiben, bu çalışmada takipçi sayısına bağlı olarak üç özel hastane üzerine odaklanılmıştır. Bunlar; Aralık 2017 itibarıyla 18.800 takipçisi olan Medical Park ${ }^{11}$, 31.200 takipçisi olan Memorial Sağlık ${ }^{12}$ ve 26.000 takipçisi olan Acıbadem Sağlık ${ }^{13}$ hastane gruplarıdır. Belirlenen bu üç hastane grubu 
Ocak-Eylül 2018 döneminde Instagram sayfalarında çeşitli video ve fotoğraflar kullanmıştır. Ekim 2018 itibarıyla toplamda Acıbadem Sağlık 1564, Memorial 1786 ve Medikal Park 1735 gönderi paylaşmıştır (Tablo 1).

Facebook ve Twitter kullanan Üniversite Hastaneleri, dikkati çekecek bir biçimde Instagram'da varlık göstermemektedir. Buna ek olarak, dermatolojik durumlar ve hamilelik ile ilgili konularda ise kullanıcıların kişisel deneyimlerini paylaşmak için Instagram'ı kullandıklarını gösteren çok sayıda etiket bulunduğundan hastane isimlerine bu yolla da ulaşılmıştır.

Araştırma kapsamında belirlenen üç hastanenin Instagram hesaplarında, OcakEylül 2018 tarihleri içinde yer alan toplam 876 adet görselde belirtisel gösterge imgeleri incelenerek hangi temalara referans verdiği anlaşılmaya çalışılmıştır. Görsellere ait metinler de içerik analizi yöntemi kullanılarak sınıflandırılmıştır. İçerik çözümlemesi kodlama cetvelindeki sınıflandırma bu çalışmada şu şekilde belirlenmiştir. Bunlar; yaşam biçiminin temsili, başarı hikâyeleri ve aile ve çocuktur. İçerik analizi değişkenleri; 1. Yaşam biçiminin temsili: Instagram'da paylaşılan fotoğraflarda sağlıklı yaşama ilişkin temsillerin yer alıp almadığı ele alınmıștır. 2 . Başarı Hikâyeleri: Paylaşılan fotoğraflardaki başarılı hasta hikâyelerinin vurgulandığı resim veya videolar incelenmiştir. 3. Aile ve Çocuk: paylaşılan fotoğraflarda hem hamile kadınlara öneriler ve bilgilendirmeler veren hem de ebeveynlere çocukları için sağlık önerileri veren fotoğraf ve mesajlara bakılmıştır.

Tablo 1'de araştırma kapsamında ele alınan hastanelerin Instagram hesaplarının genel görünümü sunulmaktadır. İçerik analizi yöntemi ile 9 aylık (Ocak-Eylül 2018) zaman dilimi içerisinde 876 Instagram gönderisinin karşılıklı etkileşim düzeyi ve içeriği açıklanmıştır. Buna göre Instagram'da 1520 fotoğraf/video ile Medical Park en fazla görüntüyü paylaşırken bunu 1400 fotoğraf/video ile Memorial takip etmektedir. Hastanelerin takipçileri yani hedef kitleleri açısından değerlendirildiğinde 31.100 takipçi ile Memorial ilk sırayı alırken onu 26.000 takipçi ile Acıbadem ve 18.800 takipçi ile Medical Park izlemektedir.

Tablo 1: Hastanelerin toplam takipçi ve gönderi sayıları

\begin{tabular}{|l|c|c|c|c|c|}
\hline & $\begin{array}{c}\text { Toplam } \\
\text { Takipçi Sayısı } \\
\mathbf{1 . 1 0 . 2 0 1 8}\end{array}$ & $\begin{array}{c}\text { Toplam Gönderi } \\
\mathbf{1 . 1 0 . 2 0 1 8}\end{array}$ & $\begin{array}{c}\text { Takipçi Sayısı } \\
\mathbf{0 1 . 0 1 . 2 0 1 8}\end{array}$ & $\begin{array}{c}\text { Toplam Gönderi } \\
\mathbf{0 1 . 0 1 . 2 0 1 8}\end{array}$ & $\begin{array}{c}\text { Toplam Gönderi } \\
\mathbf{0 1 . 0 1 . 2 0 1 8 -} \\
\mathbf{3 1 . 0 9 . 2 1 0 1 8}\end{array}$ \\
\hline $\begin{array}{l}\text { Acıbadem } \\
\text { Hastanesi }\end{array}$ & 26.000 & 1564 & 14.800 & 1.153 & 359 \\
\hline Medical Park & 18.800 & 1.735 & 9.530 & 1.520 & 204 \\
\hline Memorial & 31.100 & 1.786 & 16.000 & 1.400 & 313 \\
\hline
\end{tabular}

\section{Bulgular}

Bu çalışmada Ocak-Eylül 2018 tarih aralığında incelenen üç özel Ankara hastanesinin - Medical Park, Memorial Sağlık ve Acıbadem Sağlık - Instagram hesaplarında yer alan görseller ve görsel başlıkları, içerikleri temel alınarak üç kategoriye ayrılmıştır. Bu kategoriler aşağıda verilen tabloda hastanelerin toplam gönderi sayıları belirtilerek verilmiştir (Tablo 2). 
Tablo 2: Hastanelerin belirlenen kategoriler içinde Ocak-Eylül 2018 döneminde gönderi sayısı

\begin{tabular}{|l|c|c|c|}
\hline & Yaşam biçiminin temsili & Perde arkası & Aile ve Çocuk \\
\hline Acrbadem Hastanesi & 220 & 37 & 53 \\
\hline Medical Park & 113 & 16 & 39 \\
\hline Memorial & 234 & 5 & 42 \\
\hline
\end{tabular}

Belirlenen üç kategori için Hastanelerin Instagram hesaplarında yer alan 876 adet görsel incelenmiş ve 759 gönderinin bu kategoriler içinde yer aldığı tespit edilmiştir. Geriye kalan 117 adet gönderi de toplum için önemli gün ve bayram kutlamaları ve sosyal sorumluluk projelerini içermektedir.

1. Yaşam biçiminin temsili: İncelenen üç Ankara özel hastanesinin Instagram sayfalarında yer alan görseller, sağlıklı bir yaşamın nasıl olmasına gerektiğine ilişkin temsiller içermektedir. Görseller aracılığı ile hastaneler, insanların hayat kalitelerini nasıl iyileştirmeleri gerektiğine yönelik mesajlar vermiştir. Instagram hesaplarındaki beslenme, stres yönetimi, egzersiz, tıbbi kontrollerin sıklı̆̆ına ve düzenine özen gösterilmesi ve kişiler arası ilişki ve sağlık sorumluluğu konuları gibi başlıklar altında yer alan görseller ile hedef kitlelerine sağlıklı yaşam donanımlarını nasıl geliştirecekleri vurgusu yapılmaktadır.

Bu kategoride en fazla paylaşımı yapan Memorial'ın Ocak-Eylül 2018 dönemi içinde toplam 313 iletisinin 234 âdeti bu kategoride olup, Acıbadem'in 359 adet iletisinin 220 adedi bu kategori kapsamındaki görsellerden oluşmaktadır. Son olarak incelenen dönem içinde Medical Park'ın paylaştığı 204 iletinin 113’ü bu kategoriye yönelik olmuştur.

Örneğin; Acıbadem Sağlık Grubu belirlenen Ocak-Eylül 2018 tarihleri içinde "Seçimini yap, Obeziteyi Engelle", "Yemekte Su İçmeyin", "En İyi Önlem: Hareket", "Kafeine Alternatif Uyarıcı: Su", "Böbreklere Dikkat" ve "Bağışıklık Güçlendirici Turuncu" gibi bașlıklarla, fotoğraflar yüklemiștir. Medical Park ise "Kalbinizin Sesini Dinleyin”, Öksürük Bitmek Bilmiyorsa”, "Her Eklem Ağrısı Romatizma Değildir", İncir Sindirime Yardımcıdır" ve "Meyve Porsiyonlarınıza Dikkat Edin” başlıklı görseller paylaşmıștır. Son olarak Memorial Sağlık ise diğer hastanelerden farklı olarak paylaştığı gönderimlerde başlık kullanmamıș, bilgi metinlerini görsellerin altına eklemiştir. Örneğin; bir enginar resminin altına "karaciğeriniz hastaysa bu besinleri sofranızdan eksik etmeyin!", deniz kenarında çıplak ayak yürüyen bir kadın resminin altına "ıslak mayo ve terliksiz dolaşmak mantar hastalıklarına neden olabilir", yoga yapan bir kadın resminin altına "aşırı öfke karaciğere zarar verebilir!” ve meyveli yoğurt resminin altına "açlık krizlerinizi önlemek için kan şekeri dengenizi koruyun" metinleri paylaşılmıştır.

2. Başarı Hikâyeleri: Özel sağlık konuları hakkında farkındalığın artırılması için paylaşımlarda bulunan üç hastane de başarılı hasta hikâyelerini vurgulamak için resim veya videolar yayınlamıșlardır. Medikal ve sağlık hizmetlerinde gelișen teknoloji, organ nakli ile yaşama tutunan hastaların tecrübeleri, cerrahi işlemleri tamamen bütünleştirebilecek yeni kuşak cerrahi robotlarla elde edilen bașarılı sonuçları ve kanser tedavileri sonucu hastalığı yenen hastaların hikayeleri gibi başlıklarla hastaneler Instagram hesaplarında hedef kitlelerine motivasyon kazandırmayı hedeflemektedir. 
Bu kategoride en fazla paylaşımı yapan Acıbadem'in Ocak-Eylül 2018 dönemi içinde toplam 359 iletisinin 37 âdeti bu kategoride olup, Medical Park'ın 204 adet iletisinin 16 adedi bu kategori kapsamındaki görsellerden oluşmaktadır. Son olarak incelenen dönem içinde Memorial'ın paylaștığı 313 iletinin sadece 5'i bu kategoriye yönelik olmuştur.

Örneğin; Acıbadem Sağlık Grubu; "Robotic cerrahi sonucu bir hastasının sondasız yaşamı”, "15 yaşındaki bir hastanın sırtındaki eğriliklerden kurtuluş hikâyesi”, "A'dan Z'ye Böbrek Sağlığı" ve "Kızını görmek isteyen babanın kornea nakli" başlıklı gönderiler paylaşmıştır. Medical Park ise; bünyesinde bulunan doktorların çeşitli sağlık sorunları hakkındaki bilgilendirme videolarını "Uzm. Doktor Evren Toprak KOAH ve akciğer hastalıkları hakkında bilgilendiriyor", "Uzm. Doktor Ayşegül Başar tendon ve bağ yaralanmaları hakkında bilgilendiriyor" ve "Doç. Dr. A. Barış Durukan Facebook canlı yayınında Varis ve Güncel varis Tedavileri hakkında sorularınızı yanıtlıyor" başlıklarını kullanarak paylaşmıştır. Son olarak Memorial'da; "İki çocuk annesi Sibel Çilingir karaciğer nakliyle sağlığına kavuştu", "51 yaşındaki Nevin Karaçobanoğlu kanserden kurtuldu ve yepyeni bir yaşama kavuştu" ve "9 yılda iki kez beyin kanaması geçiren Banu Bayraktarbaşı, AVM hastalığını yendi" ve "Organ Bağışla Hayat Devam Etsin" başlıklarını görsel içerikle yayınlamıştır.

3. Aile ve Çocuk: Sağlık iletişimi, dijital medya ile birlikte çok daha fazla yaygınlaşmış, anne ve babalar da çocukları için sağlık konusunda gerekli bilgileri öğrenmede internete başvurmaya başlamıștır (Yılmaz ve Biricik, 2017, 183). Bu noktada incelenen üç hastanenin Instagram paylaşımları da ebeveynlere çeşitli görseller ve başlıklar aracılığı ile çocukları için anatomik, fiziksel, psikolojik, bağışıklık sistemi, metabolik ve gelişimsel başlıkları altında sağlık önerileri vermiştir. Bununla birlikte, belirlenen üç hastane Instagram paylaşımlarında ayrıca gebe kadınlara önerilerde bulunulmuş ve bilgilendirmelere yer vermiştir. Hamilelikte vücut bakımı, ruh sağlığı ve beslenme başlıkları altında paylaşılan görsellerle birlikte ayrıca tüp bebek tedavisi hakkında görseller de Instagram sayfalarında paylaşılmıştır.

Bu kategoride en fazla paylaşımı yapan Acıbadem'in, Ocak-Eylül 2018 dönemi içinde toplam 359 iletisinin 53 âdeti bu kategoride olup, Memorial'ın 313 adet iletisinin 42'si bu kategori kapsamındaki görsellerden oluşmaktadır. Son olarak incelenen dönem içinde Medical Park'ın toplamda paylaştığı 204 iletinin 39'u bu kategoriye yönelik olmuştur.

Örneğin; Acıbadem Sağlık Grubu, "Bebek Hayali Kuruyorsanız", "Alerjisi Geçmiyor Mu?" ve "Düzenini Bozmayın" başlıklarıyla gönderimler yapmıştır. Medical Park ise; "Diş Çıkarırken Ağızda Kanamalar”, "Ebeveyn Çocuk İlişkisi Dil Gelişimini Etkiliyor”, "Aşı Takvimi", "Riskli Hamilelik Tespit Edilebilir" ve "Gebelikte Cilt Hassasiyeti Oluşabilir" başlıklarıyla görseller yayınlamıştır. Son olarak Memorial Sağlık ise diğer hastanelerden farklı olarak paylaştığı gönderimler de başlık kullanmamış, bilgi metinlerini görsellerin altına eklemiştir. Örneğin; bir salata resminin altına “Tüp bebek tedavi sürecinde, tedaviye yardımcı olacak beslenme önerilerimize göz atabilirsiniz", kitap okuyan bir kız çocuğu resminin altına "Yaz tatiline çocuğunuza okuma alışkanlığı gibi güzel alışkanlıklar kazandırın!” ve bir köpekle yan yana duran küçük bir kız resminin altına "Çocukların duygusal ve sosyal gelişiminde önemli bir rol oynayan hayvan sevgisinin küçük yaşlardan itibaren aşılanması gerekir" metinleri paylaşılmıştır. 
Her üç hesapta Ocak-Eylül 2018 döneminde toplamda 876 adet iletide benzer tip görselleri ve mesajları her gün olmak üzere Instagram hesaplarında paylaşmışlardır. Bu hesaplar, hizmet ettikleri kişilerin çeşitliliğine odaklanmakta ve tavsiyelerde bulunarak sağlık koşullarıyla ilgili farkındalık yaratmayı amaçlamaktadırlar. Her üç hesapta Instagram'ı yaratıcılık ve hikâye anlatımı platformu olarak kullanmaktadır. Hesaplar, belirli prosedür veya sağlık hatlarını desteklemektedir. Başlık ve fotoğraflarının altlarına konularında uzmanlaşmış sağlık görevlileri tarafından bilgilendirme mesajları yazılarak paylaşımların içerikleri zenginleştirilmiştir. Örneğin; Acıbadem, paylaştığı bir fotoğrafının altına sondasız yaşamla ilgili hastasının bir mesajını yazmıștır. Kısacası, bu hesaplar, gönderdikleri iletiler ve mesajlar aracılığıyla basitçe "bilgilendirme tohumları" atmaktadır.

Bununla birlikte, her üç hesapta Ocak-Eylül 2018 dönemi içinde toplumsal açıdan önemli görülen günlere ilişkin paylaşımlara yer vermeleri dikkat çekicidir. Öte yandan hesapların üçü de takipçileri ile Instagram üzerinden bir etkileşim oluşturma eksikliği yaşamaktadır. Topluluk etkileşimi başlatmak için bir etiket oluşturmamışlardır. Oluşturulan etiketleri takip etmekte ve sık sık "Google Images" resimleri kullanmaktadırlar. Ayrıca, bu hesaplar bu platformu herhangi bir bağış toplama etkinliğine yönelik olarak da kullanmamaktadırlar. Örneğin; Çocuklar için Shriners Hastaneleri, ${ }_{14}$ "Așkla Kurtarma” kampanyası yapmakta ve çocukları iyileştirmek için binlerce kişiye ulaşmaktadır.

Yine de, Türkiye'deki özel hastanelerin sosyal medya bilinci ve kullanımı artmaktadır. Bu çalışmada seçilen hastanelerin sosyal medya üzerindeki etkinliği araştırma süresi boyunca artmıştır. Hastalar sağlık hizmetlerine yönelik olarak iletişim kurmak ve bilgi paylaşmak için sosyal medyayı giderek daha fazla kullanmaktadırlar. Bu, Sağlık 2.0 veya Tıp 2.0 (Belt vd., 2010) olarak tanımlanan kavramların temellerinden biridir. Hastalar, sosyal medyada kendi hikâyelerini ve bilgilerini paylaşmakta ve bu bilgiler Google gibi arama motorları tarafindan hızla endekslenerek kolayca bulunabilmektedir. Birçok hastanın Google aramaları ile tedavi sürecine başladıkları göz önüne alındığında, sağlık kuruluşlarının sosyal medyada etkin olmasının önemi görülmektedir. Özetle, sosyal medyanın aktif kullanımı iletişim hızını arttırmakta ve hastalar için bilgi akışını geliştirmektedir.

\section{Sonuç}

Günümüzde kurumlar yeni iletişim teknolojilerini kullanarak hedef kitlelerine daha yakın olma ve daha kolay erișebilme imkânı elde etmiştir. Özellikle görsel bir temele dayanan içerik paylaşım sitesi Instagram aracılığıyla kurumlar hem ürün ve hizmetlerini tanıtabilmekte hem de takipçilerinin kurum ya da ürün ve hizmetle ilgili soru, öneri, beklenti, istek, şikâyet ya da problemlerine aracısız doğrudan çözüm sunabilmektedir. Araştırmada, SGK ile antlaşması olan Ankara'daki üç özel hastanenin Instagram hesapları Ocak-Eylül 2018 tarihleri arasında incelenmiștir. Bulgularda öne çıkan sonuçlardan birisi, bu kurumların sosyal medyayı sağlıkiletişimi maksatlı kullanmalarıdır. Hastanelerin Instagram hesaplarından paylaştıkları gönderilerin içeriklerine bakıldığı zaman daha çok sağlıklı yaşama yönelik önerilerin, başarılı tedavi süreçlerinin ve aile-çocuk konusu hakkında tavsiyelerin paylaşıldığı belirlenmiştir. Hastanelerin daha çok sağlı iletişimi amaçlı paylaşımları daha fazla yer alırken, marka reklam amaçlı kullanmadıkları görülmüştür. Hastanelerin Instagram hesaplarından paylaştıkları fotoğraf ya da videoların büyük bölümü günlük olarak paylaşılmıştır. 
Hastaneler, Instagram'dan paylaşılan gönderilerin altına bırakılan yorumlar sayesinde takipçilerinden geri bildirim almakta ve takipçilerinin istek, görüş ve eleştirileri hakkında kolayca bilgi sahibi olabilmektedir. Bu durum hastane ve takipçileri arasında iletişim ve etkileşimi artırmaktadır. Hastanelerin gerek paylaşımlarının içerikleri gerek paylaşımlarının altında kullandıkları metinler ya da başlıklar hastanelerin Instagram'ı yoğun şekilde sağlıklı yaşam hakkında öneri amaçlı kullandıklarını göstermektedir.

Sosyal medyanın hayata girmesi ile sağlık hakkında bilgi edinimi değișmiștir (Giustini, 2006, 1283-1284). Artık, akıllı telefonlar, sağlık ve sağlık hizmetleri alanındaki bir dizi sosyal öğrenmede etkili olmaktadır. Örneğin; hasta bakımı, izleme, rehabilitasyon, iletişim, tanı, öğretim ve araştırma gibi. Instagram'ın klinik iletişim ve öğretim araçlarına eklenmesi, sağlık ekiplerinin zamanında yanıt vermesini, hastane sakinleri için daha hızlı sevk edilmesini ve halk sağlığ 1 mesajlarının daha fazla insana yaygınlaştırılmasını kolaylaştırmaktadır. Geleneksel iletişim araçlarına ek hizmetler olarak kullanılan uygulamalar, sorgulama ve uygulamaya yönelik sanal topluluklar oluşturmaya, yoğun ve dağınık sağlık hizmetleri ortamlarını karakterize edecek şekilde zamansal ve psikolojik mesafelere köprü kurmaya yardımcı olmaktadır.

Hastaneorganizasyonununkendisi için deInstagram'ın yararlıyönleribulunmaktadır. Birçok çalışmada, sosyal medyanın personel arasındaki iletişimi geliştirebileceği, ağ oluşturmayı kolaylaştırabileceği, ziyaretçileri hastanenin web sayfasına çekebileceği, hastane markasını oluşturacağı ve araştırma projelerine yönelik istihdamlarda kullanılabileceği belirtilmiștir (Thielst, 2011, 66-70; Gamble, 2009, 32-34). Son olarak; bu araştırmanın dıșında sosyal medyanın sağlık hizmetlerinin iyileştirilmesinde nasıl bir rol oynayacağını da araștırmak için yeni araștırmalara ihtiyaç bulunmaktadır.

\section{Notlar}

${ }^{1} 33$ Mind-Boggling Instagram Stats \& Facts for 2017. https://www.wordstream.com/blog/ws/2017/04/20/instagramstatistics. Erişim Tarihi, 27.12.2017

${ }^{2}$ Digital in 2018 Global Overview. https://wearesocial.com/blog/2018/01/global-digital-report-2018. Erişim tarihi, 21.01.2019

${ }^{3}$ Instagram Statistics.https://www.omnicoreagency.com/instagram-statistics/. Erişim tarihi, 25.01.2019

4 Mashable. Obama's re-election was big on Instagram, too. http://mashable.com/2012/11/08/instagramelectionobama/. Erişim tarihi, 12.12.2017

${ }^{5}$ Instagram Statistics.https://www.omnicoreagency.com/instagram-statistics/. Erişim tarihi, 25.01.2019

${ }^{6}$ Instagram Türkiye'de 22 milyon kullanıcıya ulaştı. https://www.ntv.com.tr/teknoloji/instagramin-turkiyedekikullanici-sayisi-22-milyonu-gecti,oMpXa3Xj5Eugj4CP1APUwA. Erişim tarihi, 06.09.2016

${ }^{7}$ Türkiye'de Sosyal Medya Kullanımı. https://crovu.co/turkiyede-sosyal-medya-kullanimi/, Erişim tarihi, 12.12.2017

${ }^{8}$ Ahava Leibtag, "The 10 Best Hospitals on Instagram". https://ahamediagroup.com/blog/2016/06/the-10-besthospitals-on-instagram-and-why/. Erişim Tarihi, 25.12.2017

${ }^{9}$ https://www.instagram.com/p/BnllV1pgRY4/. Erişim Tarihi, 19.08.2018

${ }^{10} \mathrm{https}$ ://gss.sgk.gov.tr/OzelSHSBilgi/. Erişim Tarihi, 19.12.2017

${ }^{11} \mathrm{https}: / /$ www.instagram.com/medicalparkhg/

${ }^{12} \mathrm{https}: / / w w w . i n s t a g r a m . c o m / m e m o r i a l s a g l i k / ? h l=e n$

${ }^{13} \mathrm{https}: / / w w w . i n s t a g r a m . c o m / a c i b a d e m s a g l i k / ? h l=e n$

${ }^{14}$ https://www.instagram.com/shrinershospitals/?hl=en. Erişim tarihi, 19.06.2018 


\section{Kaynakça}

Al-Eisa, E., Al-Rushud, A., Alghadir, A., Anwer, S., Al-Harbi, B., Al-Sughaier, N., Al- Yoseef, N., Al-Otaibi, R. ve Al-Muhaysin,H. A. (2016). Effect of Motivation by “Instagram" on Adherence to Physical Activity Among Female College Students. BioMed Research International, 6 pages. http://dx.doi. org/10.1155/2016/1546013. (21.12.2017).

Bilgin, K. R. (2013). Savaşı Anlamak için Savaş Çalışmalarını Anlamak. The Journal of National Security and Military Sciences, September, 1, 1, 25-56.

Boulos, M. N., Maramba, I. ve Wheeler, S. (2006). Wikis, Blogs and Podcasts: A New Generation of Web-based Tools For Virtual Collaborative Clinical Practice and Education. BMC Medical Education, 6: 41. https://doi.org/10.1186/14726920-6-41. (21.12.2017).

Boulos, M. N., Wheeler, S., Tavares, C. ve Jones, R. (2011). "How Smartphones Are Changing The Face of Mobile and Participatory Healthcare: An Overview With Example From ECAALYX", Biomed Eng. Online, 10: 24. https://biomedicalengineering-online.biomedcentral.com/articles/10.1186/1475-925X-10-24. (21.12.2017).

Boulos, M. N, Brewer, A. C., Karimkhani C, Buller, D. B. ve Dellavalle, R. P. (2014). Mobile Medical and Health Apps: State of The Art, Concerns, Regulatory Control and Certification. Online J. Public Health Inform, 5, (3) e229. (21.12.2017).

Chou, W. Y., Hunt, Y. M., Beckjord, E. B., Moser, R. P. ve Hesse, B. W. (2009). Social Media Use in The United States: Implications For Health Communication. Journal of Medical Internet Research, 11(4): e48. (21.12.2017).

Chou, W. Y., Liu, B., Post, S., Hesse, B. (2011). Health-Related Internet Use Among Cancer Survivors: Data From The Health Information National Trends Survey, 2003-2008. Journal of Cancer Survivorship, Sep 5 (3), 263-70.

Cool, C. T., Claravall, M. C., Hall, J. L., Taketani, K., Zepeda, J. P., Gehner, M. ve LaweDavies, 0. (2015). Social Media as a Risk Communication Tool Following Typhoon Haiyan. Western Pacific Surveillance and Response Journal, 6 (Suppl. S1), 86-90.

Gamble, K. H. (2009). Just a Tweet Away. Healthcare Informatics, 26(5): 30-34.

Gauthier, T. P., Bratberg, J., Loi, K. ve DiVall, M. V. (2016). Delivery Of Educational Content Via Instagram. Medical Education, 50, 575-576.

Giustini, D. (2006). How Web 2.0 is Changing Medicine. BMJ, 333, 1283-1284. http:// www.bmj.com/content/333/7582/1283. (22.12.2017).

Karpathy, A. and Fei Fei, L. (2014). Deep Fragment Embeddings for Bidirectional Image Sentence Mapping. Advances in Neural Information Processing Systems 27 (NIPS 2014), (ED: Z. Ghahramani, M. Welling, C. Cortes, N.D. Lawrence and K.Q. Weinberger). Paper presented at Neural Information Processing Systems 2014, Montreal, 8-13 December (pp. 1412-1421).

Kravitz, R. L. ve Bell, R. (2013). A Media, messages, and medication: strategies to reconcile what patients hear, what they want, and what they need from medications. BMC Medical Informatics and Decision Making, 13 (3), 5. 
Lee, E., Lee, J. A., Moon, J. H. ve Sung, Y. (2015). Pictures Speak Louder than Words: Motivations for Using Instagram. Cyberpsychology, Behavior, and Social Networking, 18, 552-556.

McIver, D. J., Hawkins, J. B., Chunara, R., Chatterjee, A. K., Bhandari, A., Fitzgerald, T. P., Jain, S. H. ve Brownstein, J. S. (2015). Characterizing Sleep Issues Using Twitter. Journal of Medical Internet Research, 17 (6), e140.

Miller, A. R. ve Tucker, C. (2013.) Active Social Media Management: The Case Of Health Care. Information on Systems Research, 24(1): 52-70.

Moorhead, S. A., Hazlett, D. E., Harrison, L., Carroll, J. K., Irwin, A. ve Hoving, C. (2013). A New Dimension of Health Care: Systematic Review of The Uses, Benefits, and Limitations of Social Media for Health Communication. Journal of Medical Internet Research, 15(4), e85.

Powers, B. R. ve McLuhan, M. (2015). Küresel Köy. : İstanbul: Scala Yayıncllık.

Rıfat, M. (1996). Göstergebilimin Kitabı. İstanbul: Düzlem Yayınları.

Sadilek, A. ve Kautz, HÇ (2013). Modeling the Impact of Lifestyle on Health at Scale. Proceedings of the 6th ACM International Conference on Web Search and Data Mining, 637-646.

Sanlav, Ü. (2014). Sosyal Medya Savaşları. İstanbul: Hayat Yayıncılık.

Sayın, Z. (2007). Gösteren-Gösterilen İlişkisi Açısından Grafik Göstergeler ve Göstergeleri Algılayış Farklılıkları. Semio İstanbul 2007 (“Görünürün Kültürleri” Konulu 8. Uluslararası Görsel Göstergebilim Kongresi kitabı), Cilt 2, İstanbul: İstanbul Kültür Üniversitesi Yayınları.

Suby, C. (2013). Social Media in Health Care: Benefits, Concerns, and Guidelines for Use. Creative Nursing, 19(3), 140-147.

Thielst, C. B. (2011). Using Social Media to Engage Patients: Many Tools Exist to Connect, Communicate and Build Loyalty. Healthcare Executive, 26(3): 66- 70

Tiggemann, M. ve Zaccardo, M. (2015). Exercise to Be Fit, Not Skinny: The Effect of Fitspiration Imagery on Women's Body Image. Body Image, 15, 61-67.

Van De Belt, T. H., Engelen, L. J., Berben, S. A. ve Schoonhoven, L. (2010). Definition of Health 2.0 and Medicine 2.0: A Systematic Review. Journal of Medical Internet Research, 12(2), e18.

Vygotsky, L. S. (1978). Mind in Society: The Development of Higher Psychological Processes. Cambridge, MA, USA: Harvard University Press.

Walker, M., Thornton, L., Choudhury, M. D., Teevan, J., Bulik, C. M., Levinson, C. A. ve Zerwas, S. (2015). Facebook Use and Disordered Eating in College-Aged Women. Journal of Adolescent Health, 57, 157-163.

Wheeler, S. (2015). Learning with 'e's: Educational Theory and Practice in the Digital Age. : Carmarthen, UK: Crown House Publishers.

Yılmaz, A. ve Biricik, Z. (2017). Sağlık İletişiminde Dijital Medya Kullanımının Çocuk Sağlı̆ı Üzerine Etkileri: Sosyal Medya ve Çevrimiçi Oyunlar Üzerine Bir İnceleme. Atatürk İletişim Dergisi, 14, 173-184. 
Yi-Frazier, J. P., Cochrane, K., Mitrovich, C., Pascual, M., Buscaino, E., Eaton, L., Panlasigui, N., Clopp, B. ve Malik, F. (2015). Using Instagram as a Modified Application of Photovoice For Storytelling and Sharing in Adolescents With Type 1 Diabetes. Qualitative Health Research, 25, 1372-1382. 
